\title{
Critical Evaluation of Scientific Websites by High School Students
}

\author{
Marie Iding, Robert E. Landsman and ThanhTruc T. Nguyen
}

Educational Psychology Department, University of Hawaii, Honolulu, Hawaii, USA

miding@hawaii.edu

ANOVA Science Education Consulting, Honolulu, Hawaii, USA

Curriculum Research and Development Group, University of Hawaii, Honolulu, Hawaii, USA

Keywords: internet, secondary teaching, classroom teaching/practice, critical evaluation

\begin{abstract}
This study describes an instructional intervention in which high school biology students leamed to develop criteria for critically evaluating science Websites and scientific information contained in them. Results indicated that the process of learning to critically evaluate Websites was what was most valuable to them. Students' lists of criteria for critically evaluating Websites were more extensive after instruction. Furthermore, the majority of students reported learning something new, indicated that they would spend more time evaluating scientific information on Websites, and reported increased confidence in their ability to evaluate scientific information on the Web.
\end{abstract}

\section{INTRODUCTION}

The question of the validity or credibility of information on the World Wide Web is a growing concern to educators, parents, students, and others. As students are encouraged to engage in project-based research, more of their information is from the Web where anyone can publish anything at anytime. Teachers frequently assume that students have learned how to critically evaluate Website information sources and that it is the responsibility of other teachers (most often English teachers) to have covered this topic (Nguyen 2000). This often inaccurate assumption underscores the need for students to learn to evaluate information sources, 
and for teachers to learn to carry out instruction that effectively facilitates this process in all content areas.

This concern is especially important in the area of science learning because students as beginning scientific researchers, or at the very least, lifelong consumers of scientific information, must be able to adequately assess claims and make judgments about scientific information in general, not just information on the World Wide Web. This aspect of scientific literacy is deemed to be essential by the American Association for the Advancement of Science in Benchmarks for Science Literacy (1993):

"In everyday life, people are bombarded with claims - claims about products, about how nature or social systems or devices work, about their health and welfare, about what happened in the past and what will occur in the future. These claims are put forth by experts (including scientists) and nonexperts (including scientists), by honest people and charlatans. In response to this barrage, trying to separate sense from nonsense, knowledge helps." (p. 298)

Learning to critically assess information is important in part because of the proliferation of non-refereed material on the Internet. It is also imperative due to the movement away from single-textbook-based science teaching where judgments of accuracy of information were outside the purview of teachers and students, and in the hands of textbook writers and editors. Accuracy judgments have been placed into the hands of individual students and teachers who are very likely to have not experienced instruction in how to effectively make those judgements. Therefore, in this paper we examine work that provides a needed foundational research base for students' critical evaluation of Web-based scientific information, then we describe a study in which we worked with high school students to facilitate their development of individual and group criteria to evaluate scientific information on Websites.

Prior work in this area includes research that develops criteria for evaluating Websites or, frequently, software and/or multimedia in general (e.g., Chen 1995, Sherry 1998, Nguyen 2000). Chen (1995) for example, provided an interesting approach that evaluated the pedagogical techniques employed by software, according to learning theories. Sherry (1998) described an exercise in which she had students develop a "multimedia matrix" for developing their own multimedia. Although this approach was employed at the graduate level, her suggestions for student personalization of the matrix could well be adapted for students at other levels evaluating Websites.

An innovative approach was developed by Nguyen (2000) where high school students in three different subject areas, including science, created an 
evaluation tool called $O A S I S$ to use in selecting appropriate resources from the World Wide Web. Teachers surveyed in Nguyen's study also indicated that they allow Web resources for student research more than other multimedia resources such as CD-ROMs, videotapes, audiotapes, and television shows. Though these latter four multimedia resources usually have editing and review bodies, it is the resources from the Web that are most accepted by teachers (Nguyen 2000).

Other research examined ways that scientists and others evaluate the credibility of information sources generally (e.g., Klemm, Iding and Speitel, in press). In that research, Klemm, Iding, and Speitel (in press) found that preservice elementary and secondary science teachers and scientists rated the credibility of many science information sources differently, with scientists ascribing less credibility to most sources listed, with the exceptions of PBS television (public television) and a scientist researching a question, which they rated as more credible. Interestingly, elementary teachers rated popular investigative weekly television newsmagazines like $20 / 20$ as among the highest in credibility, while scientists rated them as among the lowest. This research underscores the need for developing critical judgement skills in the general population.

In addition to this research, there are a number of Websites that present criteria for evaluating Websites and the information contained in them. Two such Websites are the Internet Detective (http://sosig.ac.uk/desire/internetdetective.html) by the Desire Project and ICYouSee: $\mathrm{T}$ is for Thinking (http://www.ithaca.edu/library/Training/hott.html) by Henderson of Ithaca College Library. Also, Dr. T. Matthew Ciolek, in conjunction with the World Wide Web Consortium, maintains a Website entitled Information Quality WWW Virtual Library (http://www.ciolek.com/WWWVLInfoQuality.html) dedicated to keeping track of online resources relevant for evaluation, development and administration of high quality factual/scholarly networked information systems. However, many of the lists of criteria on the Web are unaccompanied by actual research.

To address the lack of extensive research in this area, the present project was undertaken. The current work was carried out in two sections of an inquiry-, project-based high school biology classes. In this class, students learn how to approach scientific problems and how to solve problems experimentally using scientific methodology. Students also learn how to apply probability theory to decision making through the use of statistics, design and carry out their own experiments, and communicate about their studies through APA style written and oral reports.

One of the central features of this endeavor is actual library and Web research. In conjunction with the actual gathering of appropriate resources, students make assessments about the validity of material. As a result, the 
authors were interested in providing students with the opportunity to examine and further develop their own criteria for the assessing information from the Web. It was hoped that students would understand the importance of critically evaluating scientific Websites and the information contained in them. In the rest of the paper, we explain how the process was facilitated and evaluated, and discuss the impact of the process on the students.

\section{METHOD}

\subsection{Participants}

Participants were students in two senior biology classes at the University of Hawaii Laboratory School. The students are from diverse ethnic, ability, and socioeconomic backgrounds reflective of Hawaii's population. The ethnic breakdown consists of approximately $38 \%$ mixed ethnicity (including part-Hawaiian), 18\% Caucasian, 18\% Filipino, 16\% Japanese and $10 \%$ other (including Asian, Pacific Islanders, AfricanAmerican). In the first class, participants included 10 boys and 10 girls. In the second class, participants included 9 boys and 10 girls.

\subsection{Procedure and materials}

This workshop on scientific Website evaluation took place in the students' regular biology classes, over the course of four days. The three authors, their regular biology instructor (a scientist and curriculum developer), an educational technology specialist, and an educational psychology professor co-facilitated the workshop. Below, we briefly describe the sequence of events and the materials that were used.

On the first day, students answered two pretest questions that required that they list and describe what they consider first, when deciding to use a Website in general; and, secondly, what they consider when evaluating the scientific information on the Website. They ranked the items in their lists. Then, the educational technology specialist provided a brief description of the terms Internet, World Wide Web, Websites, and individual Web pages. She also provided a general introduction to three areas to consider when evaluating Websites and the scientific information on them: credibility of authors and institutions, validity or accuracy of the information contained in Websites, and the presentation aspects or organisation of the Website and its information (e.g., layout, graphics). This characterisation of Websites is 
derived from Farah (1995) and Rader (1998) and adapted in the research of Nguyen (2000).

On the second day, students engaged in actual Website evaluations to gain experience in the critical evaluation process. They carried out written evaluations of two Websites containing scientific information about a disease. One was accurate and credible while the other contained deliberate errors and invalid information. These websites were created for educational exercises of this sort. Students compared the Websites in terms of reliability, credibility, and presentation. Then, students evaluated a third Website containing information about frogs and learning. They listed pros and cons of using the Website to look for scientific information in general, and for using information from the Website for their scientific research or scientific research papers.

On the third day, teams of 5 students developed collaborative lists containing characteristics that they determined would be important for themselves or other students like them to use in evaluating scientific information on Websites. In the second part of the class, their teacher and the educational psychology professor facilitated the development of whole-class lists on the board, via whole-class discussion of characteristics from the collaborative lists. The purpose of this activity was to facilitate students' deeper processing and refinement of their criteria.

On the fourth day, summative evaluation took place. First, using the same two questions that were used in the pretest, students created individual lists for evaluating scientific Websites generally then for determining whether to use scientific information from Websites. These items were ranked. The instructions were the same as those given for the pretest. Next, students filled out follow-up questionnaires consisting of 12 items assessing whether their views of how to evaluate scientific information on Websites had changed and how, whether their confidence in their abilities to evaluate Websites had improved, what the most important things were that they had learned, and their general suggestions and comments regarding the activities.

\section{RESULTS AND DISCUSSION}

\subsection{Did criteria for evaluating change?}

The items from the pre- and post-Website evaluation program studentgenerated lists used to evaluate scientific Websites and the science information on Websites were categorised by the experimenters into the categories validity, credibility, or presentation. The pre- and post-education 
program data for the three categories were then summarised as percent of total (Tables 1 and 2) and means (Figures 1 and 2).

Table 1. The number (in parentheses) of student-generated items used to evaluate scientific Websites generally categorised as validity, credibility, or presentation and expressed as preand post-education program percent of totals and change in percent of totals

\begin{tabular}{lcccc}
\hline & Validity & Credibility & Presentation & Total \\
\hline Pre & $51 \%(80)$ & $40 \%(63)$ & $9 \%(15)$ & $100 \%(158)$ \\
Post & $45 \%(116)$ & $32 \%(83)$ & $23 \%(59)$ & $100 \%(258)$ \\
Change & $-6 \%(+36)$ & $-8 \%(+20)$ & $+14 \%(+44)$ & \\
\hline
\end{tabular}

Table 2. The number (in parentheses) of student-generated items used to evaluate scientific information on Websites categorized as validity, credibility, or presentation and expressed as pre- and post- Website evaluation program percent of totals and change in percent of totals

\begin{tabular}{llllc} 
& \multicolumn{1}{c}{ Validity } & \multicolumn{1}{c}{ Credibility } & \multicolumn{1}{c}{ Presentation } & \multicolumn{1}{c}{ Total } \\
\hline Pre & $63 \%(79)$ & $27 \%(33)$ & $10 \%(10)$ & $100 \%(158)$ \\
Post & $52 \%(136)$ & $27 \%(69)$ & $21 \%(55)$ & $100 \%(258)$ \\
Change & $-11 \%(+57)$ & $0 \%(+36)$ & $+11 \%(+45)$ & \\
\hline
\end{tabular}

As can be seen in Tables 1 and 2, for both the Website and information on the Website, the percent of total was the highest for validity-related items, followed by credibility-related items and then presentation-related items. Analyses of variance indicated that when the number of items for the three categories were combined, students generated significantly more evaluative items for both scientific Website and for scientific information on Website evaluation after participation in the Website evaluation program [Pre vs Post mean \pm S.E.M.: $1.32 \pm .121$ vs $2.15 \pm .168, F(1,119)=19.7, p<0.00003$; $1.03 \pm .109$ vs $2.17 \pm .209, F(1,119)=37.0, p<0.00000002$, respectively] Although the number of student-generated items appeared to be greater following participation in the Website evaluation program, the percent of totals changed in the positive direction only for presentation-related items (Tables 1 and 2). This indicates that the web evaluation program may have had the most impact on student awareness of the presentation aspects of scientific Website and information evaluation.

Figures 1 and 2 present the mean number of student-generated items for the three categories before (Pre) and after (Post) the web evaluation program. 


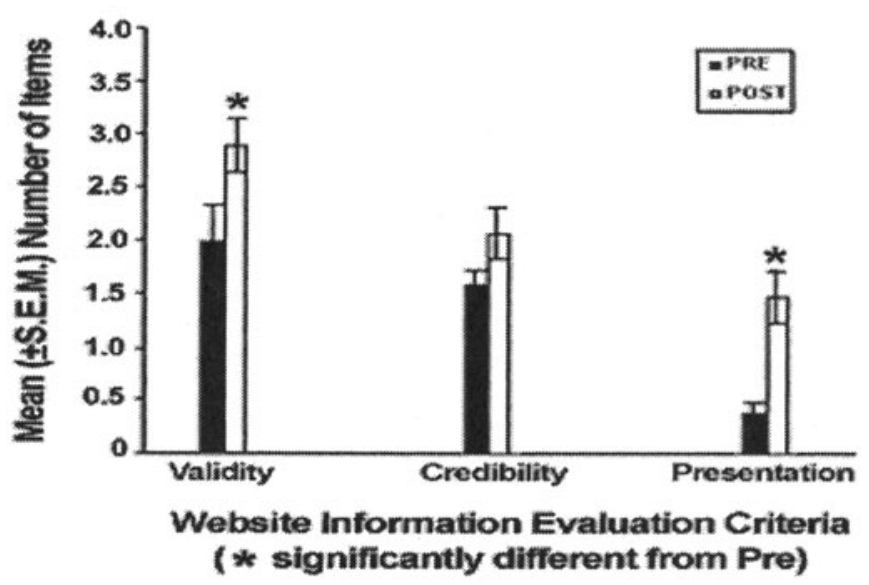

Figure 1. Means for general Website evaluation criteria

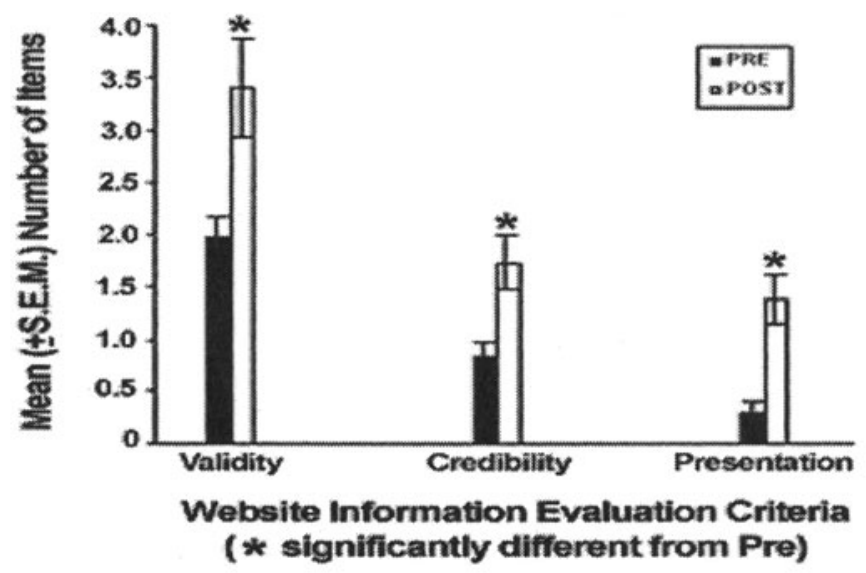

Figure 2. Means for scientific information criteria

For both scientific Websites (Figure 1) and scientific information found on Websites (Figure 2), the number of student-generated items was significantly higher following the Website evaluation program for validity $[t(\mathrm{df}=39)=-2.05, p<0.05$ and $t(\mathrm{df}=39)=-3.29, p<0.003$, respectively] and presentation $[t(\mathrm{df}=39)=-4.70, p=0.0001$ and $t(\mathrm{df}=39)=-4.51, p=0.0001$, respectively]. The number of student-generated credibility-related items 
following the Website evaluation program was significantly greater for scientific information found on Websites than before the program $[t(\mathrm{df}=39)=-3.40, p<0.002]$. However, the Website evaluation program did not significantly effect the number of student-generated credibility-related items used for evaluating scientific Websites [see Figure $1, t(\mathrm{df}=39)=-1.90$, $p>0.05]$.

\subsection{Had students' evaluation processes changed ?}

On a scale ranging from 'not at all' $(0 \mathrm{~mm})$ to 'moderately' $(7.4 \mathrm{~mm})$ to 'very much' $(14.8 \mathrm{~mm})$ on the post-program evaluation questionnaire, students indicated that the Website evaluation program moderately (mean=7.94 mm) changed their views of how they should evaluate scientific information on a Website. According to $80 \%$ of the students, this change in view was due to the process of creating and discussing their lists of items; $20 \%$ attributed the change in view to the actual lists that they created. One student wrote, "I think that what changed my views was the exercise in general, bringing attention to the problem of false Websites." Ninety-percent of the students indicated that, in the future, they will spend more time evaluating scientific Websites before using the information.

The majority of students (75\%) involved in the Website evaluation program claimed they had learned something new about evaluating scientific information on Websites. Comments from student's about specific ways their views of how to evaluate scientific information changed included validity, credibility, and presentation characteristics. For example, "There are phony Websites and checking a Website is important when researching a specific topic, especially when you want to use the information as a source for your scientific paper", "I learned to always check an author's credentials before using his/her information," and "The way a site looks. Is it organized, readable, eye-catching, pictures, diagrams, etc?"

Students also indicated that they realised that presentation in itself does not justify believing the information presented in a Website: "A nice looking Website does not mean it's credible. There are many more ways of determining if a Website is good enough for use or consideration. My view is that evaluating scientific information is a little more important than I thought," and "Read carefully, don't automatically assume information is accurate if presented nicely."

When students were asked to rate the importance of the process of learning to critically evaluate information on scientific Websites ( $1=$ not at all important, $2=$ of little importance, $3=$ important, $4=$ very important, and $5=$ absolutely necessary), the mean rank (3.8) indicated they considered this process of learning to be between important and very important. Student 
ranks about the process were significantly related to their level of confidence in their ability to evaluate scientific information on Websites $[r(N=40)=.60$, $\left.p<0.005, r^{2}=.36\right]$. Ninety-five percent of the students felt that their confidence about their ability to evaluate scientific information on Websites improved as a result of this Website evaluation program.

\section{CONCLUSION}

Clearly, educational activities facilitating students' critical evaluation of scientific information on Websites and the Websites themselves can be effective. In the present research, students indicated that the process of learning to critically evaluate Websites was what was most valuable to them. Additionally, students' lists of criteria for critically evaluating Websites were more extensive after instruction, and included more presentationrelated criteria. The majority of students in this study reported learning something new, agreed that they would spend more time evaluating scientific information on Websites, and reported that their confidence in their ability to evaluate scientific information of the Web had increased.

The ability to critically evaluate scientific information, such as the information on Websites, is consistent with the American Association for the Advancement of Science (1993) description of scientific literacy, and is necessary as more and more scientific information is disseminated on the World Wide Web and referenced by students for research projects. This is, in turn, important as these students disseminate their own scientific research reports and contribute to scientific and educational databases on the Web. As future directions for educational programs and/or research endeavours, we recommend working with students at all levels and in all content areas to facilitate their critical Website and information evaluation skills.

\section{REFERENCES}

American Association for the Advancement of Science (1993) Benchmarks for Scientific Literacy: Project 2061. Oxford University Press, New York.

Chen, M. (1995) A methodology for characterizing computer-based learning environments. Instructional Science, 23, pp. 183-220.

Farah, B. (1995) Information literacy: retooling evaluation skills in the electronic information environment. Journal of Educational Technology Systems, 24 (2), p. 127.

Klemm, E. B., Iding, M. and Speitel, T. (in press) Do scientists and teachers agree on the credibility of media information sources? International Journal of Instructional Media, 28 (1). 
Nguyen, T. T. (2000) OASIS: Student Evaluation Methods for World Wide Web Resources. Unpublished master's thesis, University of Hawai' i, Honolulu, Hawaii, U.S.A.

Rader, H. (1998) Library Instruction and Information Literacy. Reference Service Review, 26 (3/4), p. 143.

Sherry, A. C. (1998) Evaluation of multimedia authoring instruction based in a behavioristcognitive-constructivist continuum. International Journal of Instructional Media, 25(2), pp. 201-216.

\section{BIOGRAPHY}

Dr. Marie Iding is an Associate Professor in the Educational Psychology Department at the University of Hawaii. Her research interests include scientific visualisation and text processing with multimedia systems. She teaches courses in learning and cognition.

Dr. Robert Landsman is a neuroscientist whose scientific research focuses on neuroendocrinology and psychoneuroimmunology. He recently founded ANOVA Science Education Consulting (5223A Kalanianaole Highway, Honolulu, HI. 96821, anovaone@aol.com) where he is a science research education consultant. Dr. Landsman is interested in science education reform through the integration of scientific research into high school science curricula.

Miss ThanhTruc Nguyen is an Instructional Designer with the Curriculum Research and Development Group at the University of Hawaii. Her research interests include marine science education, technology integration in non-traditional settings, and the development of Web use standards for middle school and high school students. 